\title{
Hormonal changes and redox imbalance in nicotine-induced testicular toxicity: the mitigating influence of D-ribose L-cysteine
}

\author{
Victor O. Ukwenya ${ }^{1 *}$ D. Toluwase S. Olawuyi ${ }^{1}$, Afodun M. Adam² and Moses U. Ukwenya ${ }^{3}$
}

\begin{abstract}
Background: The effects of D-ribose L-cysteine on nicotine-induced testicular toxicity in male Wistar rats were examined in this study. Twenty healthy adult male Wistar rats with an average weight of $200 \mathrm{~g}$ were grouped as normal control, nicotine (2 mg/kg), D-ribose L-cysteine (30 mg/ $\mathrm{kg})+$ nicotine $(2 \mathrm{mg} / \mathrm{kg})$, and D-ribose L-cysteine (30 $\mathrm{mg} / \mathrm{kg}$ ). The animals were administered intraperitoneally for 35 days consecutively. Epididymal sperm concentration, motile count, total counts, morphology, and progressive assessment were estimated. Antioxidant levels, tissue protein and testicular histology were also assessed.

Results: This study showed reduced antioxidant levels (catalase, super-dioxide dismutase, and glutathione peroxidase) and increased malondialdehyde levels in the nicotine group relative to normal control group, D-ribose L-cysteine group and D-ribose L-cysteine + nicotine group. This study also showed significant reduction in testicular mass, sperm motile count, concentration, total count, and morphology in nicotine group $(p<0.05)$ compared to normal control group and D-ribose L-cysteine groups. There was improvement in sperm motility, viability, morphology, counts, in group co-treated with D-ribose L-cysteine, and nicotine relative to nicotine group. Likewise, the degenerative seminiferous tubule histoarchitecture due to nicotine was improved by D-ribose L-cysteine. Notably, the D-ribose L-cysteine group showed superlative values in all investigated parameters relative to the other groups.

Conclusion: This study demonstrated the ability of D-ribose L-cysteine to mitigate the toxic effects of nicotine on reproductive functions in male Wistar rats. It also demonstrated the pro-spermatogenic properties of the compound in boosting andrological parameters.
\end{abstract}

Keywords: Nicotine, D-ribose L-cysteine, Antioxidant levels, Germplasm, Histoarchitecture

\section{Background}

For thousands of years, nicotine in the tobacco compartment has been used by man. It has been used in many ways, but often in smoked types, at least in the Western world. Nicotine is the main alkaloid in tobacco that has been reported to have adverse effects on reproductive functions of males. It is an extremely toxic substance that can be rapidly transferred through the respiratory

\footnotetext{
* Correspondence: voukwenya@futa.edu.ng

${ }^{1}$ Department of Human Anatomy, School of Health and Health Technology,

Federal University of Technology, Akure, Nigeria

Full list of author information is available at the end of the article
}

system, oral mucosa, and skin (Sobhani et al. 2019). Cotinine is a nicotine metabolite with a lengthy half-life.

Spermatogenesis is adversely impacted by nicotine and cotinine. Epididymal sperm count, motility and eggfertilizing ability is also affected (Aydos et al. 2001). Oral and intraperitoneal nicotine administration in masculine rats has been correlated with testicular degeneration, cytoarchitecture disorganization, and decreased concentrations of serum testosterone, decreased sperm features, and longevity (Oyeyipo et al. 2010; Ukwenya, 2019)

D-ribose L-cysteine is an exclusive ribose and cysteine derivative. D-ribose L-cysteine efficiently moves through

\section{Springer Open}

(๑) The Author(s). 2020 Open Access This article is licensed under a Creative Commons Attribution 4.0 International License, which permits use, sharing, adaptation, distribution and reproduction in any medium or format, as long as you give appropriate credit to the original author(s) and the source, provide a link to the Creative Commons licence, and indicate if changes were made. The images or other third party material in this article are included in the article's Creative Commons licence, unless indicated otherwise in a credit line to the material. If material is not included in the article's Creative Commons licence and your intended use is not permitted by statutory regulation or exceeds the permitted use, you will need to obtain permission directly from the copyright holder. To view a copy of this licence, visit http://creativecommons.org/licenses/by/4.0/. 
the digestive tract and provides to the cell the brittle cysteine molecule, making it possible to produce glutathione efficiently and naturally. The cell also uses the ribose compound in D-ribose L-cysteine as an essential component for the manufacturing of ATP, the energy supply of the body (Nagasawa, 2015). This study aimed at investigating the differential effects of D-ribose L-cysteine on nicotine-induced testicular toxicity.

\section{Materials and methods}

\section{Animal care and management}

Twenty healthy adult male Wistar rats with an average weight of $200 \mathrm{~g}$ were used for this study. The animals were assigned into four experimental groups of five (5) rats each (group A, B, C, and D) after two weeks of acclimatization. They were housed in clean plastic cages which contained wood shavings, in a clean environment of 12-h light/ 12-h dark cycle at room temperature of about $30^{\circ} \mathrm{C}$. Animals in all groups were fed on rat pellet feed obtained from Chikun feeds, Akure, and allowed access to water ad libitum. All procedures involving animals in this study were done in accordance with the National Institutes of Health Guide for the Care and Use of Laboratory Animals (NRC, 2010). Clearance was obtained from the University Ethical Committees on the Use of Animals for Research.

\section{Drugs and chemicals}

Pure nicotine was purchased from Sigma Company, Germany and was administered at a daily dose of $2 \mathrm{mg} /$ $\mathrm{kg}$ body weight. D-ribose L-cysteine was purchased from the Max International, Salt-lake City, USA and was administered at a dose of $30 \mathrm{mg} / \mathrm{kg}$ body weight. The route of administration for both drugs was through intraperitoneal injection.

\section{Animal treatment}

The animals were treated as follows: Group A (Control group) received $3 \mathrm{ml}$ of normal saline, group B (Nicotine only) animals were administered intraperitoneal injections of nicotine at $2 \mathrm{mg} / \mathrm{kg}$ body weight per day, group $\mathrm{C}$ (D-ribose L-cysteine + nicotine) animals were administered intraperitoneal injections of D-ribose L-cysteine at $30 \mathrm{mg} / \mathrm{kg}$ body weight and nicotine at $2 \mathrm{mg} / \mathrm{kg}$ body weight per day while group D (D-ribose L-cysteine only) animals were administered intraperitoneal injections of D-ribose L-cysteine at $30 \mathrm{mg} / \mathrm{kg}$ body weight per day. The administration went on for five weeks. During the period of administration, body weight of the rats was monitored, taken every other day and recorded using an electronic weighing scale (WH-B Series, China) and daily food intake for each group was measured.

\section{Tissue processing}

The animals were cut open by abdominopelvic incision after sacrifice and the testes were excised and processed for histological and histochemical evaluation. The right testes were fixed in Bouin's fluid and processed for light microscopy, while the left testes were homogenized for enzyme histochemistry.

Testis tissues were processed for rapid routine paraffin embedding following fixation. The recommended procedure of Drury and Wallington (1980) was adopted. The tissues were infiltrated in two changes of molten paraffin wax at $56{ }^{\circ} \mathrm{C}$ in the oven for one hour each and finally embedded. Paraffin blocked tissues were trimmed and sectioned on microtome. The sections were spread in warm bath, and collected on clean glass slides smeared with egg albumen. The slides were then dried on a drying plate at a temperature of $40{ }^{\circ} \mathrm{C}$ overnight to enhance adherence, and stored in slide racks until ready for staining. The recommended procedure of Drury and Wallington (1980) for H\&E staining were adopted. Stained slides were mounted in Dibutylphthalate Plasticizer Xylene (DPX) using clean glass cover slips, viewed under a digital light microscope and digital photomicrographs were taken by an attached camera (Omax, USA).

\section{Biochemical evaluation}

The biochemical effects of the administered drugs were quantified by evaluating the total protein, marker of oxidative stress (malondialdehyde (MDA)), and the antioxidant enzymes: catalase, glutathione peroxidase (GPX) and superoxide dismutase (SOD).

The left testes were excised and rinsed in ice cold phosphate buffered saline pH7. All subsequent procedures were done at $4{ }^{\circ} \mathrm{C}$. The tissues were then homogenized in four volumes of homogenizing buffer per gram of tissue using a motor-driven glass-Teflon potterelvenjhem homogenizer (TRI-R STIR-R K43, USA).

The homogenizing buffer contained $50 \mathrm{mM}$ potassium sulphate (pH7.0) and $1 \mathrm{mM}$ EDTA. The homogenates were centrifuged using a bucket centrifuge at $3000 \mathrm{rpm}$ for $10 \mathrm{~min}$ to obtain clear supernatant.

The protein concentrations of the various samples were determined by means of the Biuret method as described by Gornall et al. (1949).

MDA was determined by measuring the thiobarbituric acid reactive substances (TBARS) produced during lipid peroxidation. This was carried out by the method of Varshney and Kale, (1990).

Catalase activity was determined according to the method of Claiborne (1985); GPX activity was determined according to the method of Rotruck et al. (1973) while the level of SOD activity was determined by the method of Misra and Fridovich (1972). 


\section{Seminal fluid analysis}

The right testis of each rat was used for this analysis. Semen analysis includes epididymal sperm count, sperm motility, progressive sperm motility and morphology of spermatozoa. The caudal epididymis was separated from the testis and placed in a petri dish containing $1 \mathrm{ml}$ of normal saline. The section was quickly macerated with a pair of sharp scissors and left for a few minutes to liberate its spermatozoa into the saline solution. Sperm count was performed under the microscope using the improved Neubauer chamber (Zakrzewska et al. 2002). The slide was covered with a cover slip and examined under the microscope using $\times 40$ objective lens. Sperm concentration was determined using the Neubauer improved haemocytometer. To minimize error, the count was conducted three (3) times on each of the samples obtained from the epididymis. The average of the three (3) counts from a single rat was taken and this formed an observation.

Sperm count is the total number of sperm in the entire ejaculation. To determine the sperm count, sperm concentration is multiplied by the total volume of the semen.

Sperm motility and progressive sperm motility was determined as described by Saalu et al. (2007). Sperm cell motility was assessed in a haemocytometer. Sperm motility was evaluated across a minimum five strips of squares within a $10 \mathrm{~s}$ observation time per square. The proportion of motile sperm-sperm showing a progressive movement among 100 counted sperm cells-was recorded. Non-motile sperms were first counted and then only sperms that exhibited flagella activity were taken to be motile. The motility assessment was grouped into two categories: slow (for sperm showing no noticeable motility) and fast (sperm showing sign of motility).
The morphology of the spermatozoa was obtained by utilizing the original dilution for motility, dilute/weaken 1:20 with $10 \%$ neutral buffered formalin.

\section{Statistical analysis}

GraphPad Prism (8.0.2.263) was used for statistical analysis, values were recorded as mean \pm standard error of mean (S.E.M). The statistical significance of difference in the mean and standard error of mean $(p<0.05)$ were analyzed by one-way analysis of variance (ANOVA) and the Scheffe's post hoc and Tukey's test for multiple comparison.

\section{Results \\ Testicular mass}

The result revealed that rats administered with nicotine only showed significantly lower testicular mass (1.93 \pm $0.04)$ compared to the other experimental groups $(p<0.05)$ (Fig. 1). The results also showed that rats administered with D-ribose L-cysteine recorded higher testicular mass (2.90 \pm $0.16)$ when compared with normal control group $(2.72 \pm$ $0.17)$ and D-ribose L-cysteine + nicotine group $(2.70 \pm 0.09)$ with no significant difference relative to one another.

\section{Biochemical evaluations \\ Catalase}

Data on catalase (CAT) are expressed in Fig. 2. The nicotine group $(361.8 \pm 22.02)$ showed significant $(p<$ 0.05 ) decrease in the enzymatic activity of CAT compared to the D-ribose L-cysteine group $(427.1 \pm 15.87)$. However, the result also shows the decrease of CAT activities in the rats administered with only nicotine when compared to the rats administered with both D-ribose Lcysteine and nicotine $(390.5 \pm 2.249)$ and normal control

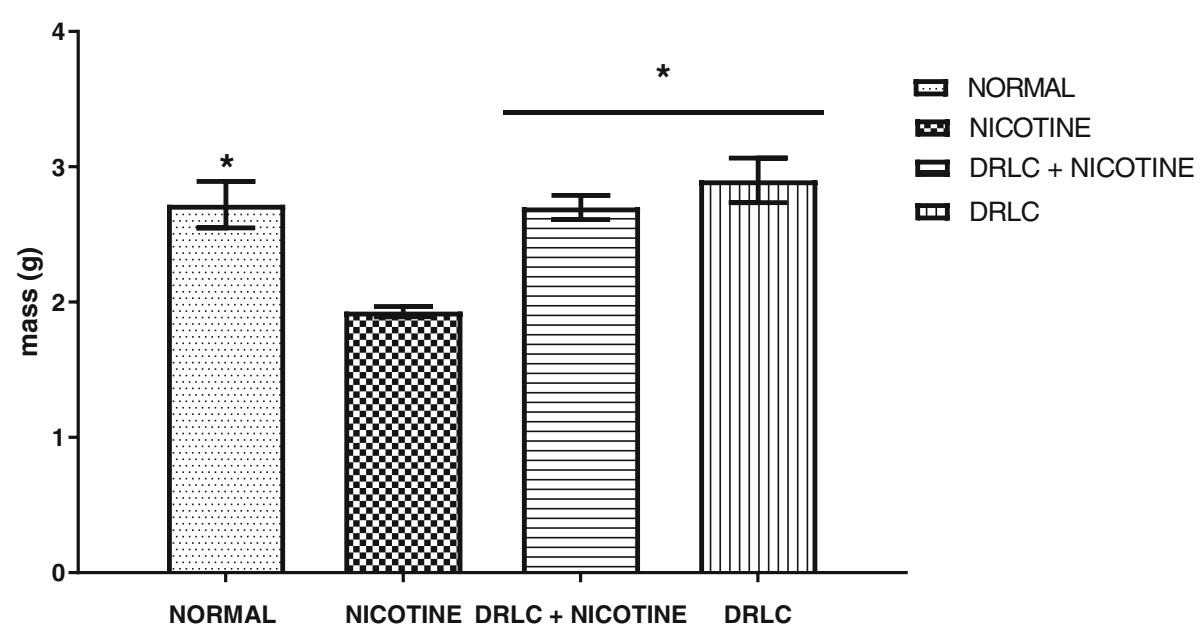

Fig. 1 Chart showing the testicular mass of the experimental animals. Values are mean \pm SEM. $N=5$. ${ }^{*}$ Statistically different from nicotine group at $p<0.05$ 


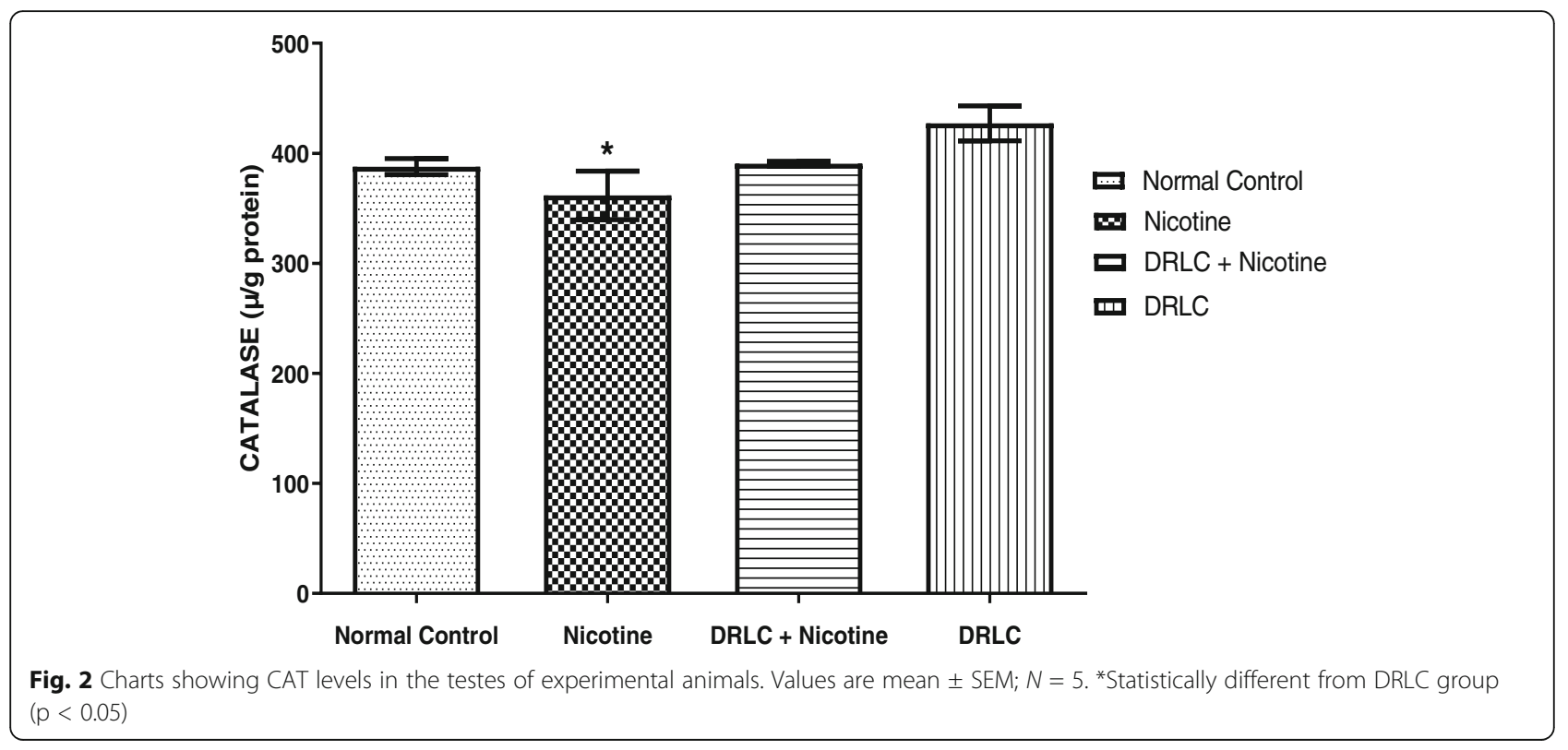

$(387.9 \pm 7.330)$ though there was no significant difference $(p<0.05)$.

\section{Superoxide dismutase}

Data on superoxide dismutase (SOD) are expressed in Fig. 3. The nicotine group showed significant decrease in the enzymatic activity of SOD $(56.43 \pm 29.12)$ compared to the normal control $(115.40 \pm 11.84)$, D-ribose L-cysteine + nicotine $(102.90 \pm 16.72)$ and the D-ribose L-cysteine group $(144.20 \pm 17.67)$ at $p<0.05$.
Glutathione peroxidase (GPX)

Data on glutathione peroxidase (GPX) are expressed in Fig. 4. The results revealed that the enzymatic activity of GPX in the nicotine group $(172.80 \pm 9.40)$ significantly decreased when compared to the normal control group $(200.90 \pm 7.60)$ at $p<0.05$. The result also showed decrease of GPX activities in the rats administered with only nicotine $(172.80 \pm 9.40)$ relative to the rats administered with only D-ribose L-cysteine $(183.20 \pm 1.60)$ and D-ribose L-cysteine + nicotine $(185.70 \pm 2.30)$ though there was no significant difference $(p<0.05)$.

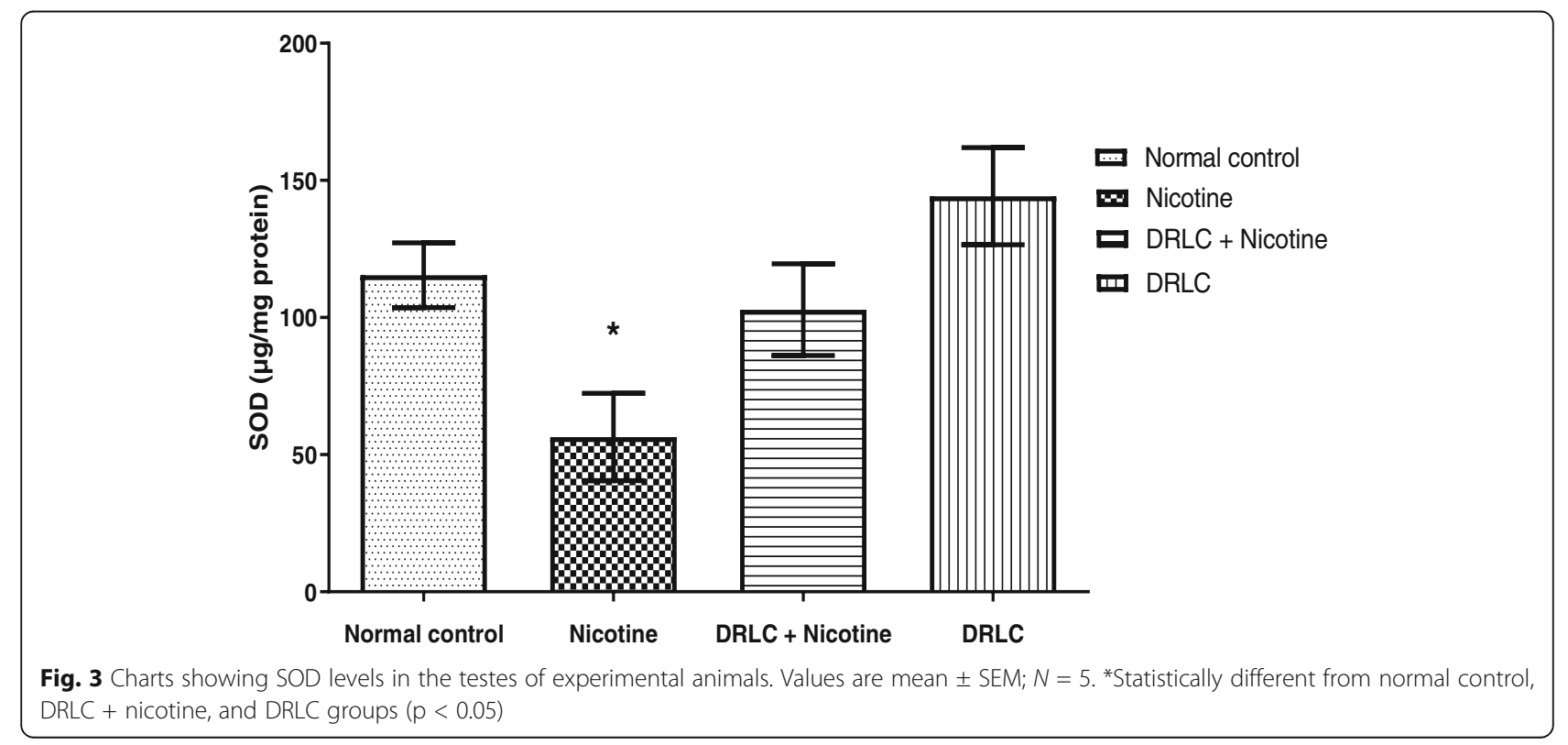




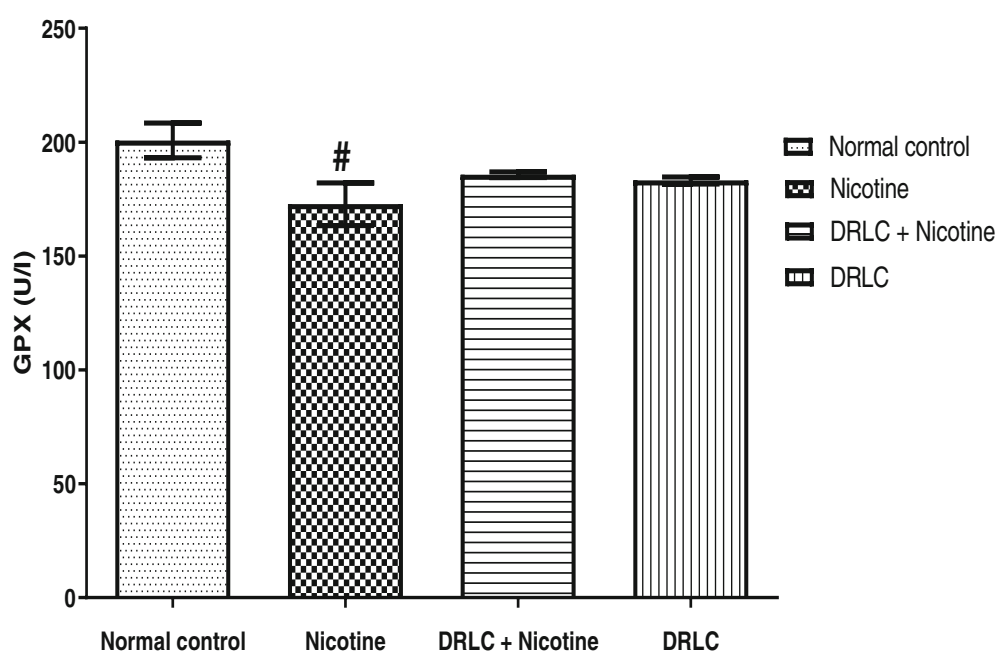

Fig. 4 Charts showing GPX levels in experimental animals. Values are mean $\pm S E M ; N=5$. "Statistically different from normal control group $(p<0.05)$

\section{Malondialdehyde (MDA)}

Data on malondialdehyde (MDA) are expressed in Fig. 5. The result revealed that the nicotine group showed significant increase in MDA levels $(0.56 \pm 0.15)$ compared to the normal control $(0.21 \pm 0.01)$, DRLC + nicotine $(0.42 \pm 0.03)$, and the DRLC groups $(0.28 \pm 0.042)$ at $p<$ 0.05 .

\section{Total protein}

Data on total protein are expressed in Fig. 6. The result as seen showed that rats treated with DRLC only had a higher level of total protein $(1.32 \pm 0.07)$ when compared to the nicotine $(1.14 \pm 0.05)$, DRLC + nicotine $(1.22 \pm 0.02)$, and normal control $(1.23 \pm 0.01)$ groups but there was no significant difference when statistically compared $(p<0.05)$.

\section{Sperm analysis \\ Sperm concentration}

The result expressed in Fig. 7 revealed that the sperm concentration for the nicotine group $(114.00 \pm 30.00)$ was the least and also statistically lower compared to the normal $(212.00 \pm 24.80)$ and the D-ribose L-cysteine groups $(250.00 \pm 37.60)$ at $p<0.05$. The concentration count for the DRLC + nicotine group (180.00 \pm 5.80$)$ was higher than the nicotine group $(114.00 \pm 30.00)$ though with no statistical difference at $p<0.05$.

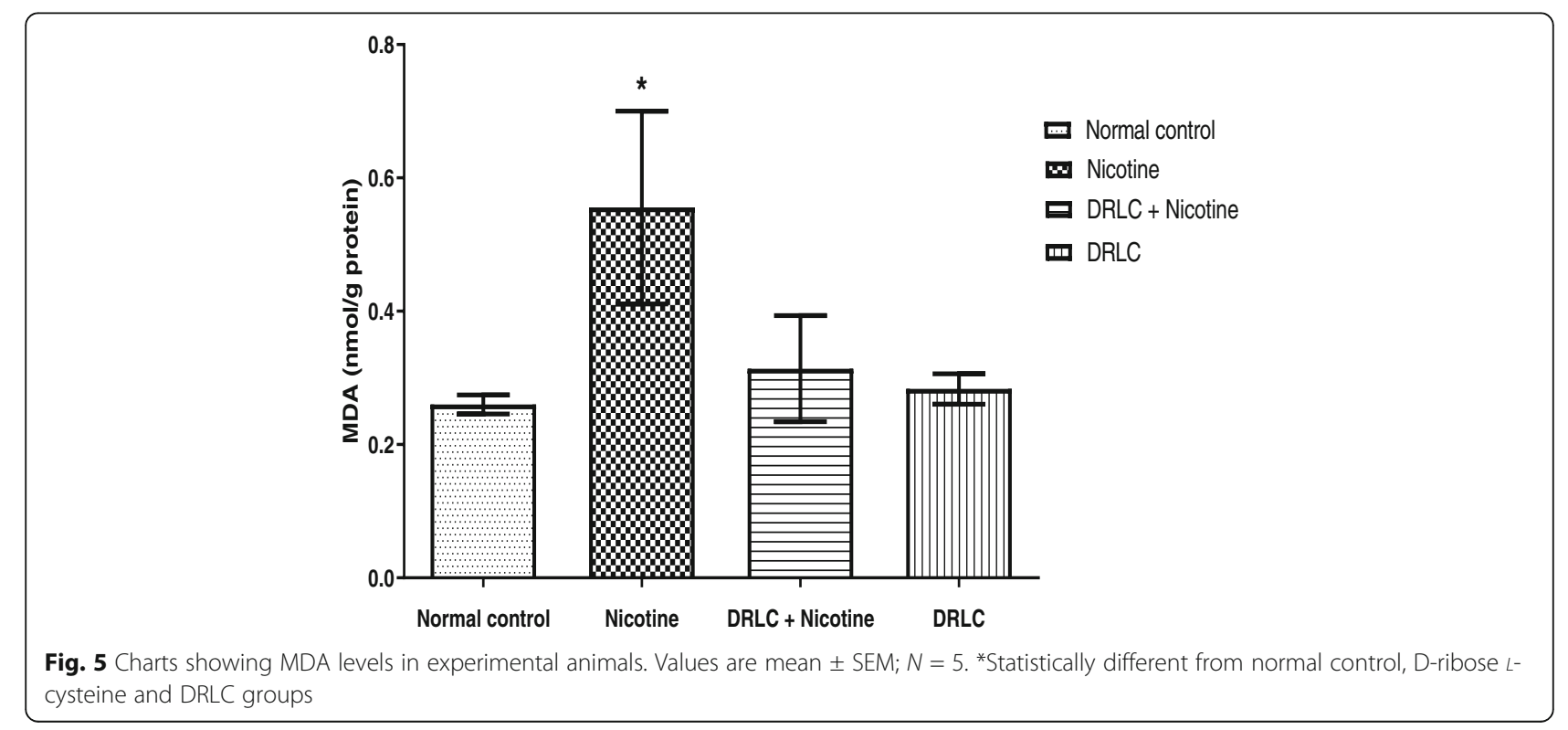




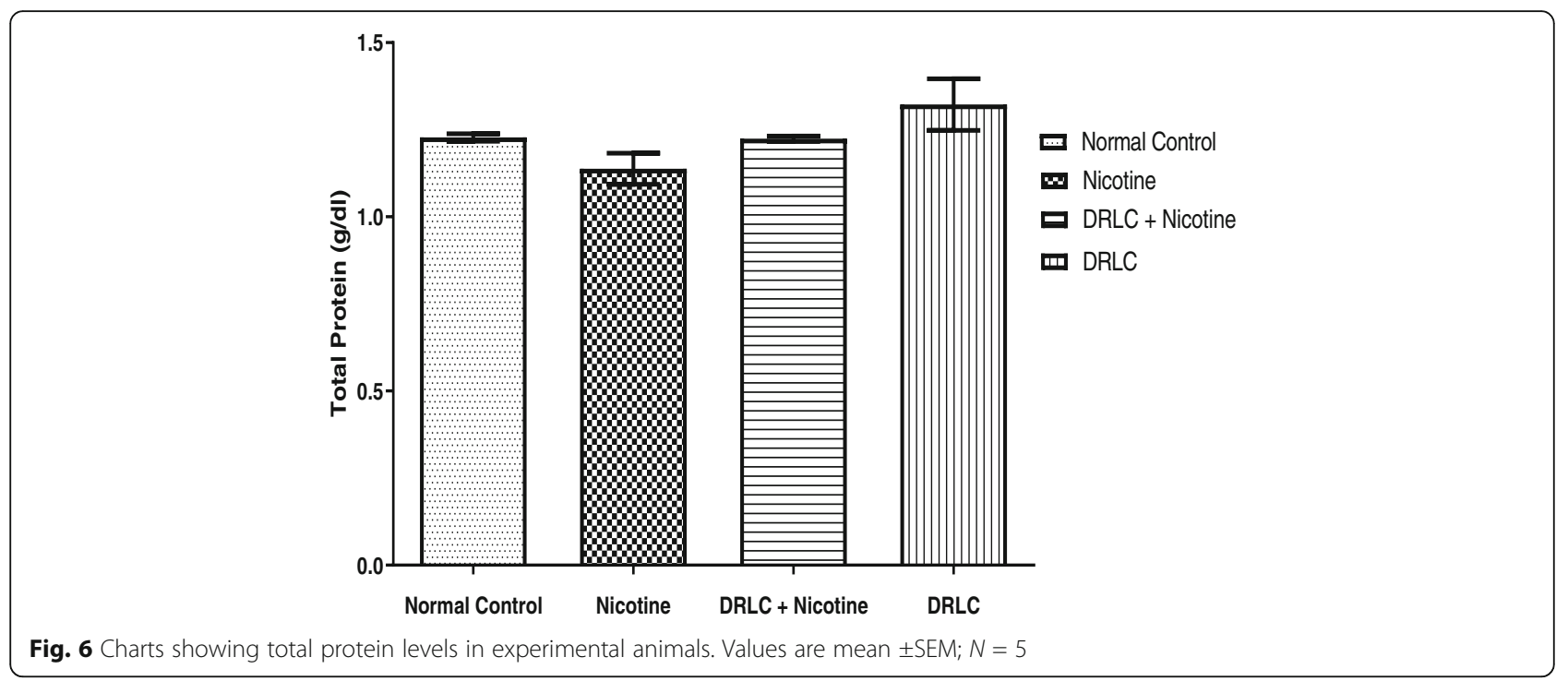

\section{Motile sperm count}

Results showed that the nicotine and DRLC + nicotine groups had the lowest motile sperm count (56.0 \pm 18.01) and $96.00 \pm 2.45$ ), which was statistically lower relative to the DRLC group (192.00 \pm 38.78$)$ and control group $(110.00 \pm 23.02)$ at $p<0.05$. The motile count for the DRLC + nicotine group $(96.00 \pm 2.50)$ was higher compared to the nicotine group $(56.0 \pm 18.01)$ but with no statistical difference (Fig. 8).

\section{Total sperm count}

Data on total sperm count are expressed in Fig. 9. The result revealed that rats treated with only nicotine showed significant decrease $(221.70 \pm 58.94)(p<0.05)$ in total sperm count compared to the normal control group $(574.40 \pm 74.37)$ and D-ribose L-cysteine group
(741.20 \pm 137.13$)$. The results also showed that rats administered with both D-ribose L-cysteine and nicotine (493.20 \pm 47.68$)$ recorded an insignificant increase in total sperm count when compared with the nicotine group (Fig. 9).

\section{Percentage sperm motility}

Data on percentage sperm motilty are shown in Fig. 10. The result revealed that rats treated with only $\mathrm{D}$-ribose $\mathrm{L}$-cysteine $(74.38 \pm 4.48)$ showed significant increase $(p<0.05)$ in percentage sperm motility compared to the normal (55.10 \pm $1.42)$, nicotine $(44.33 \pm 4.94)$ and D-ribose L-cysteine + nicotine $(50.34 \pm 4.45)$. The results also showed rats administered with both D-ribose L-cysteine and nicotine expressed an insignificant increase in percentage sperm motility when compared with nicotine-only group (Fig. 10).

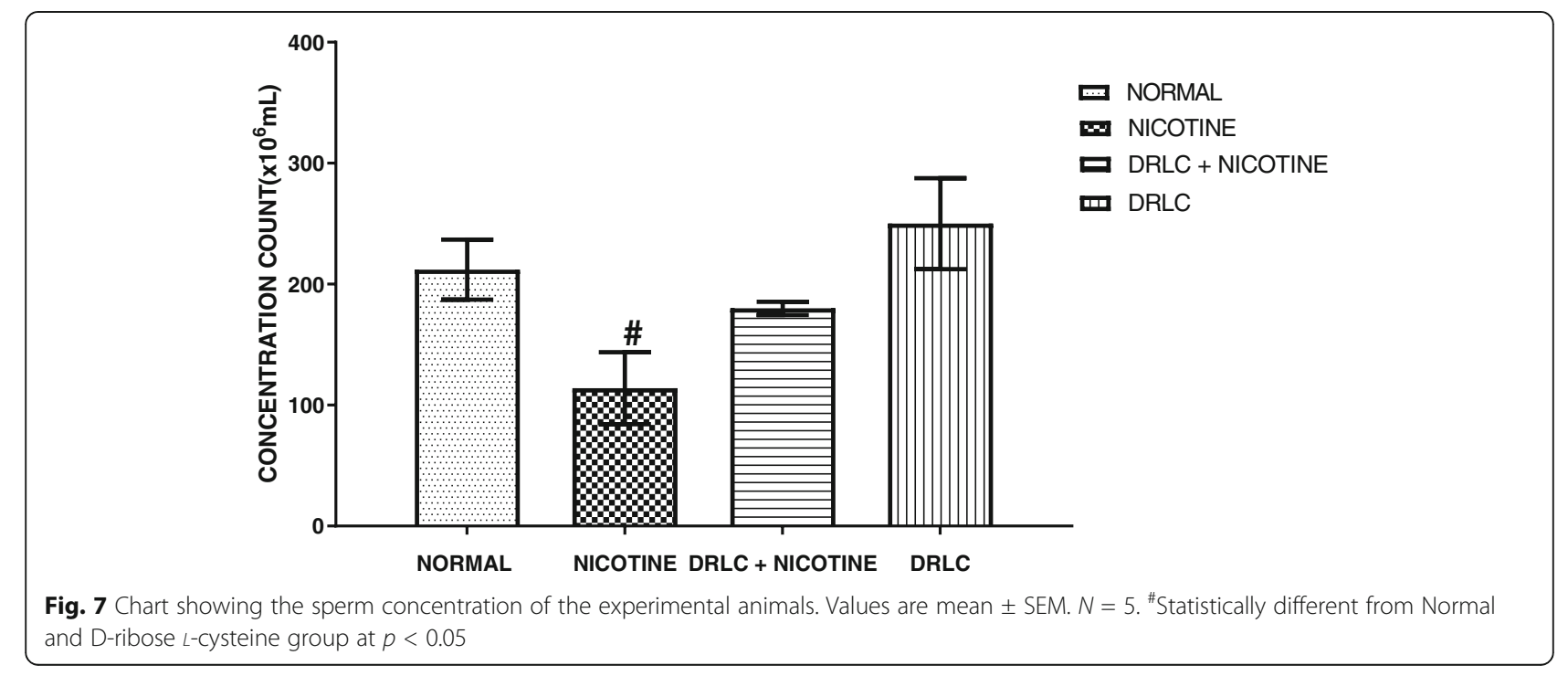




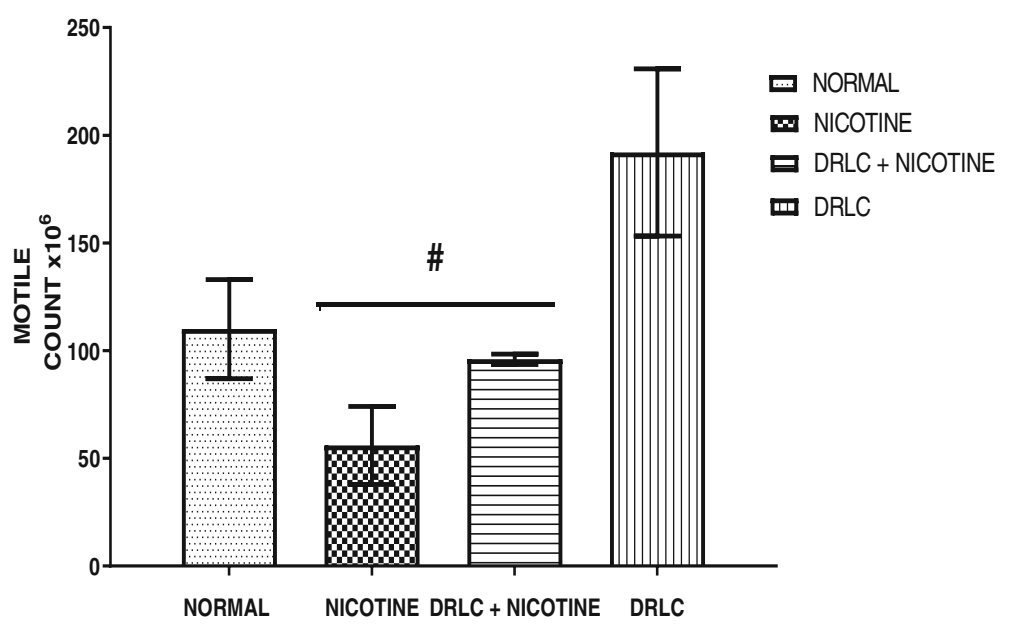

Fig. 8 Chart showing the motile sperm count of the experimental animals. Values are mean \pm SEM. $N=5$. " Statistically different from normal control and DRLC groups at $p<0.05$

\section{Sperm morphology}

Data on sperm morphology are expressed in Fig. 11. The nicotine treated rats expressed the worst results in terms of sperm morphology when compared to the remaining groups of animals. The nicotine group had the highest amount of abnormal sperms with head, neck, and tail defects. However, the D-ribose L-cysteine group had the highest amount of sperms with no defect.

\section{Fast progressive assessment}

Data on fast progressive assessment are expressed in Fig. 12. The results showed that the D-ribose Lcysteine group had the highest value for fast progressive assessment $(74.25 \pm 2.30)$ relative to the other groups i.e. normal control (63.40 \pm 0.98$)$, nicotine only (47.60 \pm 6.46) and DRLC+ Nicotine (57.00 \pm
2.00) while the nicotine only group showed the least value (47.60 \pm 6.46) (Fig. 12).

\section{Histological evaluations}

The testicular histoarchitecture of the nicotine only group (Fig. 13) showed degeneration with decreased germinal epithelial thickness and disruption of the germinal cell layers. The lumina is wide and depleted of spermatozoa compared with the normal control group (Fig. 14), D-ribose L-cysteine + nicotine group (Fig. 15) and D-ribose L-cysteine group (Fig. 16). Also, nicotine group (Fig. 13) showed irregular seminiferous tubules outline with thickened basement membrane and vacuolated cytoplasm relative to normal control group (Fig. 14), Dribose L-cysteine + nicotine group (Fig. 15) and D-ribose L-cysteine group (Fig. 16). The arteries in the interstitial

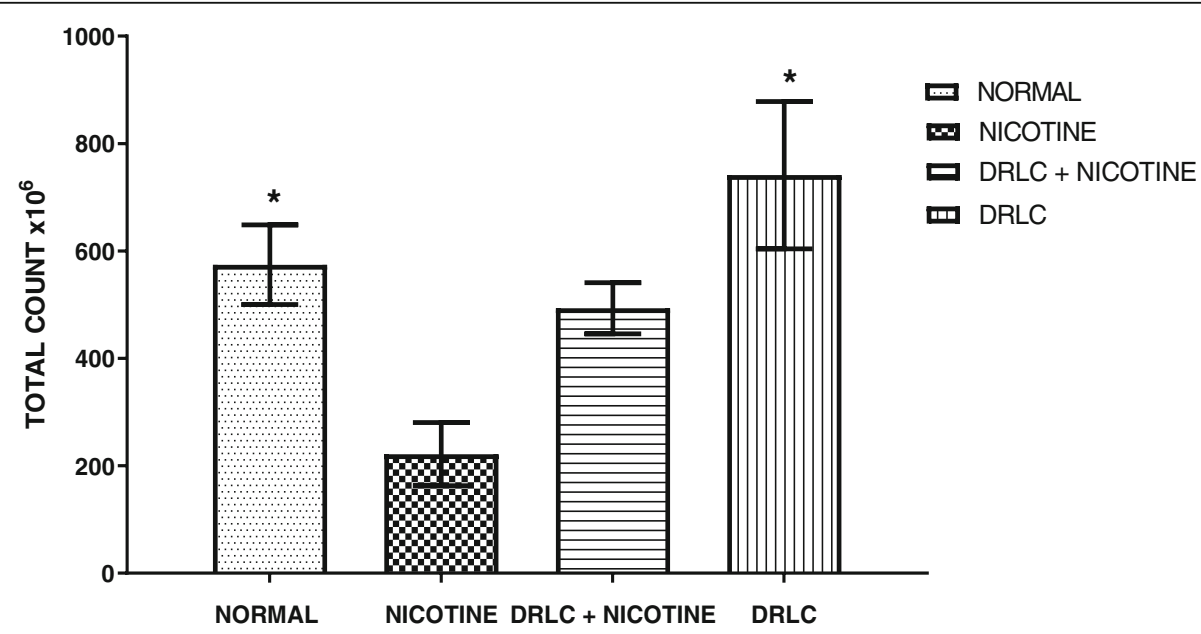

Fig. 9 Chart showing the total sperm count of the experimental animals. Values are mean \pm SEM. $N=5$. ${ }^{*}$ Statistically different from nicotine group at $p<0.05$ 


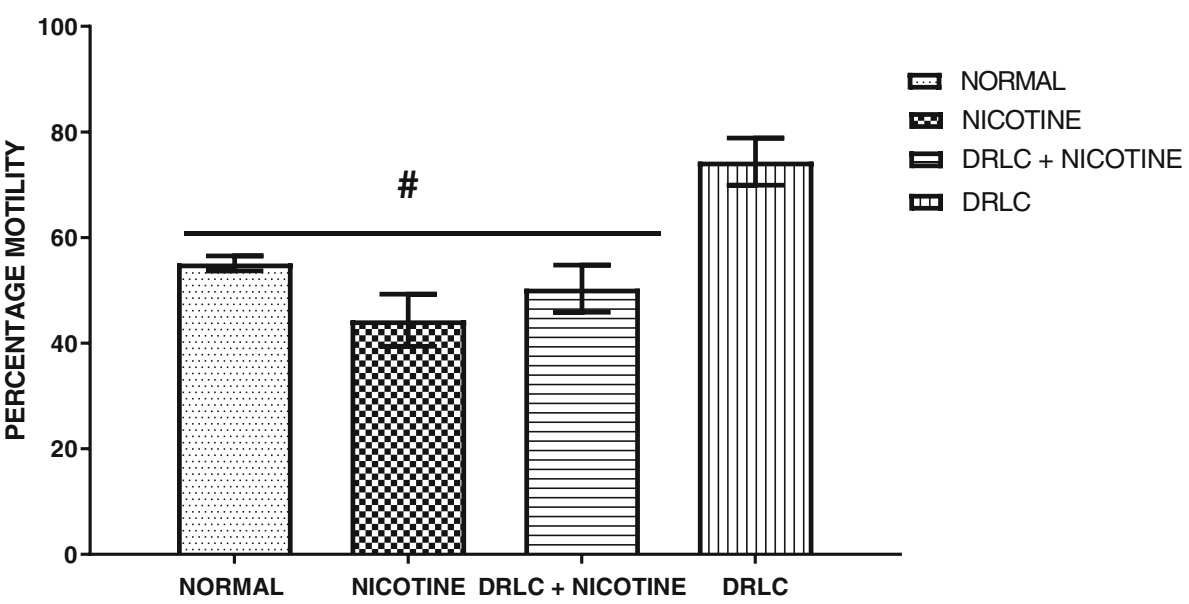

Fig. 10 Chart showing the percentage sperm motility of the experimental animals. Values are mean \pm SEM. $N=5$. "Statistically different from DRLC group, $p<0.05$

spaces of the nicotine group are markedly dilated and congested with blood.

However, testicular photomicrograph of the D-ribose L-cysteine group (Fig. 16) had similar characteristics with the normal group (Fig. 14) showing oval or circular presentation with distinctive stratified seminiferous epithelium whose lumen (L) possesses spermatogenic cells (Sp). The testicular section of the D-ribose L-cysteine + nicotine group (Fig. 15) showed restored microarchitecture of the testicular morphology showing mild distortion of the tubular architecture and disorganization of the spermatogenic cells in seminiferous tubules.

\section{Discussion}

This study was undertaken to investigate the effects of D-ribose L-cysteine on nicotine- induced testicular toxicity in Wistar rats. Nicotine also induced loss of testicular mass with changes in spermatogenesis process and decline in testicular structure, with simultaneous reduction in testicular antioxidants, elevated lipid peroxidation end-product (MDA).

The loss in testicular mass associated with nicotine treatment was correlated with histological findings which showed loss of testicular tissue. This deleterious finding was revered in D-ribose L-cysteine-treated rats. In the same trend, total protein values for the nicotine group were lowest relative to the control and D-ribose L-cysteine-treated groups. This shows the effect of nicotine on organ weight in particular; nicotine consumption is well correlated to loss of body mass.

This present study also showed that nicotine has negative effects on sperm motility, sperm count, viability, morphology, and increased the percentage of abnormal sperms. This finding is in support of the past studies

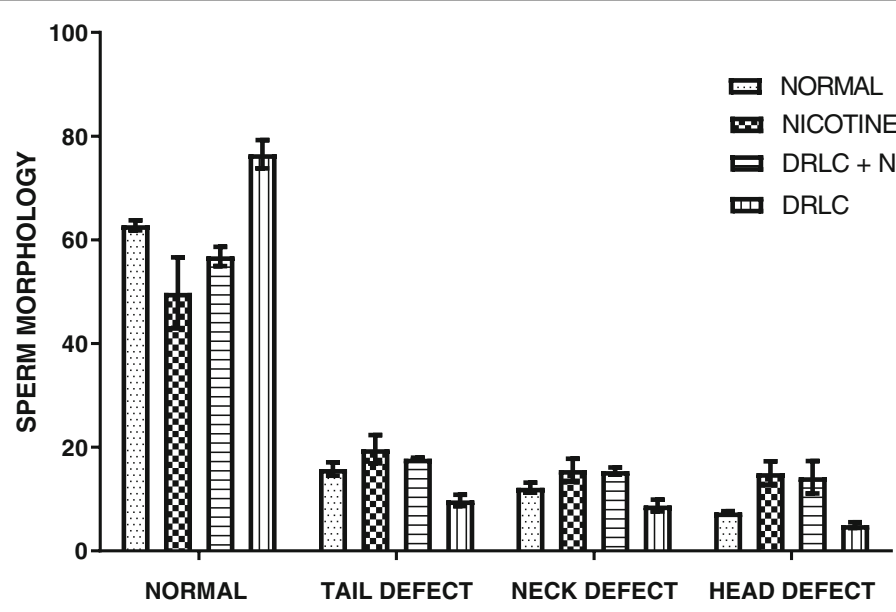

Fig. 11 Chart showing the sperm morphology of the experimental animals. Values are mean \pm SEM. $N=5$ 


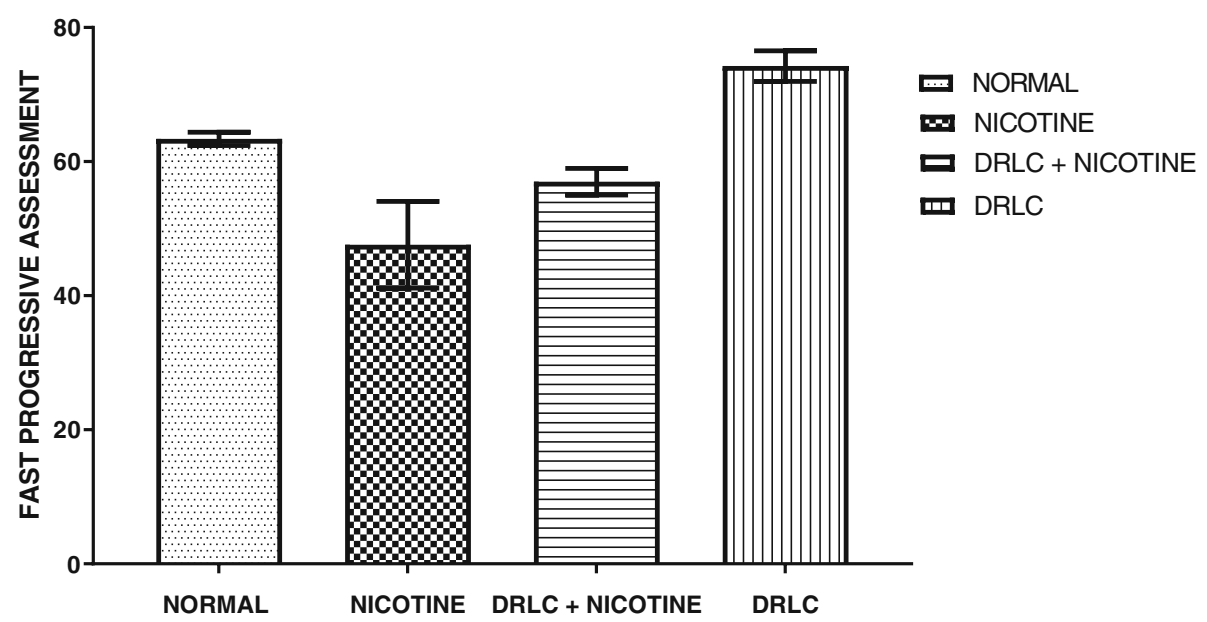

Fig. 12 Chart showing the fast-progressive assessment of the experimental animals. Values are mean \pm SEM. $N=5$

that nicotine has ability to reduce reproductive capacity and has mutagenic consequences towards the germ cell production and maturation as well as the reproductive organ itself and accessory reproductive organs (Ukwenya, 2019; Jana et al. 2010; Oyeyipo et al. 2010; Patil et al. 1999; Yamamoto et al. 1998).

Oxidative stress, through generation of reactive oxygen species (ROS), has been proposed as one of the possible mechanisms of actions of detrimental effects of nicotine on male reproductive functions. It has been proven that nicotine increased the production of ROS by increase generations of testicular $\mathrm{H}_{2} \mathrm{O}_{2}$ and hydroxyl radicals in experimental rats (Bandyopadhyaya et al. 2008). Oxidative stress has

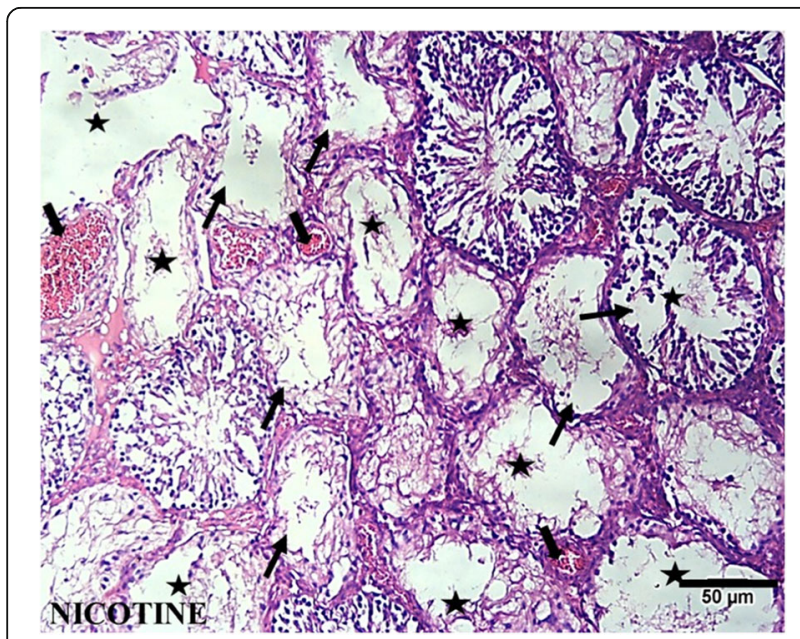

Fig. 13 Representative micrograph from the Nicotine group. Observe the irregularly shaped tubules with their atrophied germinal epithelium (arrows). The lumina is wide and depleted of spermatozoa (stars). The interstitial arteries are enlarged and congested with blood (block arrows). Stain: H\&E; Scalebar: $50 \mu \mathrm{m}$ been shown to lead to testicular damage following exposure to nicotine (Rajpurkar et al. 2000).

Findings from this study also showed that D-ribose L-cysteine at the administered dose of $30 \mathrm{mg} / \mathrm{kg}$ body weight improved spermatogenesis and sperm health by counteracting ROS. It also potentiated testicular enzymatic anti-oxidant levels and induced a reduction in lipid peroxidation end-product (MDA). These observations also included increase in total tissue protein and they agree with the work of Falana et al. (2017) which reported that the administration of Dribose L-cysteine was found to boost fertility in male Wistar rat.

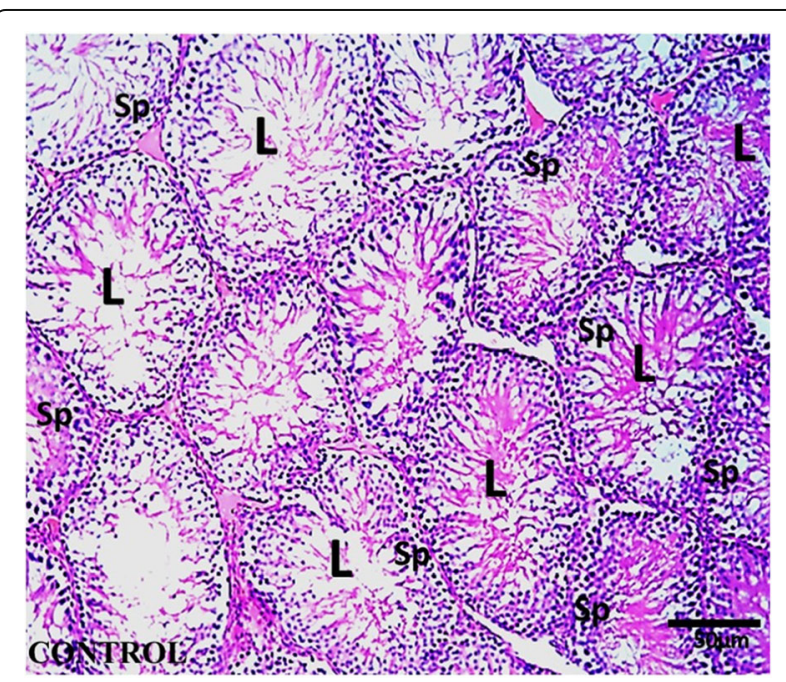

Fig. 14 Representative micrograph from the Normal Control group. Observe the oval shaped tubules with thin basement membrane containing seminiferous epithelium in which are embedded an orderly array of spermatogenic cells $(\mathrm{Sp})$. The luminal $(\mathrm{L})$ is replete with spermatozoa. Stain: H\&E; Scalebar: $50 \mu m$ 


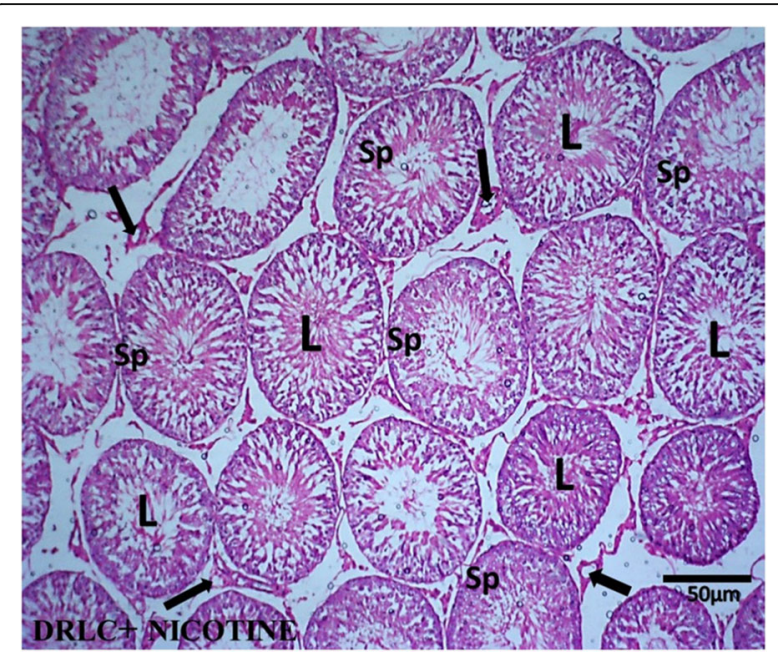

Fig. 15 Representative micrograph from the DRLC + nicotine group. Observe the seminiferous tubules with well-rounded outline. The germinal epithelium contains an array of spermatogenic cells (Sp). The lumina ( $L$ ) also contains copious quantity of spermatids. Observe the small clear, interstitial arteries (block arrows). Stain H\&E; Scalebar: $50 \mu \mathrm{m}$

The mechanism of action of the of D-ribose L-cysteine lies in the interaction between its D-ribose and L-cysteine components that facilitates the production of glutathione. Glutathione is a potent anti-oxidant within the cell that protects against destruction from free-radical damage (Gaucher et al. 2018). In this study, it was also observed that D-ribose L-cysteine attenuated the detrimental effects of nicotine on the

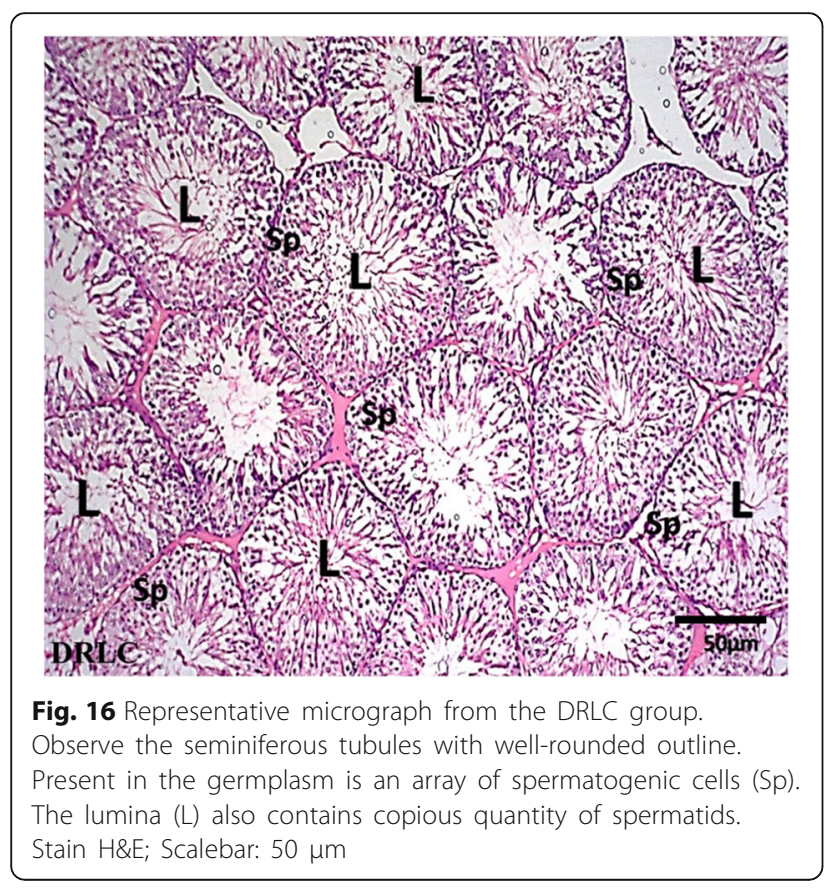

semen parameters. It is thus plausible that D-ribose L-cysteine increased the sperm volume, sperm motility, counts and morphology in this study via its counteraction of oxidative stress within reproductive organs of experimental rats.

This present study showed decrease in germinal epithelium thickness in the testicular histoarchitecture of the Nicotine only group and disruption and loss of the germinal cell layers and major pathological change in the lumen of the seminiferous tubule when compared with the other animal groups. This further demonstrates the vulnerability of the germinal epithelium to attack by cytotoxic agents. The erosion of spermatic cells in the germplasm is proof that nicotine at the administered dose of $2 \mathrm{mg} / \mathrm{kg} / \mathrm{b}$.w. was capable of crossing the bloodtestis barrier.

The D-ribose L-cysteine + nicotine and the D-ribose Lcysteine groups featured seminiferous tubules with oval or circular presentation with distinctive stratified seminiferous epithelium whose lumen possesses spermatogenic cells and prominent Leydig cells which showed similarities to the normal control group. These results are indicative of the ameliorative role of D-ribose L-cysteine in reversing nicotine-induced testicular toxicity.

\section{Conclusion}

It is instructive to note that for most of the parameters considered in this study, D-ribose L-cysteine produced superlative outcomes relative to the control and nicotine-treated groups. We therefore conclude that the administration of D-ribose L-cysteine significantly attenuated the detrimental effect of nicotine on sperm counts, motility, viability, and morphology, the testicular enzymatic antioxidant status and on the testicular histoarchitecture in Wistar rats. This study indicates that D-ribose L-cysteine may possess a protective effect against nicotine-induced impaired testicular functions in rats.

\footnotetext{
Abbreviations

DPX: Dibutylphthalate plasticizer xylene; MDA: Malondialdehyde; GPX: Glutathione peroxidase; SOD: Superoxide dismutase;

EDTA: Ethylenediaminetetraacetic acid; TBARS: Thiobarbituric acid reactive substances; DRLC: D-ribose L-cysteine; CAT: Catalase; SEM: Standard error of mean
}

\author{
Acknowledgements \\ We would like to express our sincere gratitude to Mr. Oluwole Israel \\ Ogunsola for his efforts in proof reading and type-setting the manuscript.
}

\section{Authors' contributions}

VU conceived and designed the experiment, handled tissue processing, seminal fluid analysis, statistical analysis, and developed the manuscript. TSO handled drug administration and contributed to seminal fluid analysis and tissue processing. AMA reviewed the literature, did statistical analysis, and contributed to manuscript development. MUk ran biochemical assays and contributed to statistical analysis. The author(s) read and approved the final manuscript. 


\section{Funding}

Not applicable

\section{Availability of data and materials}

Not applicable

\section{Ethics approval and consent to participate}

All procedures involving animals in this study conformed to the guiding principles for research involving animals as recommended by the guiding principles in the care and use of animals in accordance with the National Institutes of Health Guide for the Care and Use of Laboratory Animals (NIH, 2011).

\section{Consent for publication}

Not applicable

\section{Competing interests}

The authors declare that they have no competing interests.

\section{Author details}

'Department of Human Anatomy, School of Health and Health Technology, Federal University of Technology, Akure, Nigeria. ${ }^{2}$ Department of Anatomy, Faculty of Biomedical Science, Kampala International University, Kampala, Uganda. ${ }^{3}$ Department of Biochemistry, School of Sciences, Federal University of Technology, Akure, Nigeria.

Received: 3 March 2020 Accepted: 4 June 2020

Published online: 17 July 2020

\section{References}

Aydos, K., Güven, M. C., Can, B., \& Ergün, A. (2001). Nicotine toxicity to the ultrastructure of the testis in rats. BJU International, 88(6), 622-626.

Drury RAB, Wallington EA. Preparation and fixation of tissues. In: Drury RAB, Wallington EA, editors. Carleton's Histological Technique. 5. Oxford: Oxford University Press; 1980. pp. 41-54.

Claiborne, A. Catalase activity. In: Greenwald R.A., editor. Handbook of Methods for Oxygen Radical Research. CRC Press Inc.; Boca Raton: 1985. pp. 283-284.

Falana, B., Adeleke, O., Orenolu, M., Osinubi, A. and Oyewopo, A. (2017). Effect of D-ribose-L-cysteine on aluminum induced testicular damage in male Sprague-Dawley rats. JBRA Assisted Reproduction, 21 (2), 94.

Gaucher, C., Boudier, A., Bonetti, J., Clarot, I., Leroy, P., \& Parent, M. (2018). Glutathione: Antioxidant Properties Dedicated to Nanotechnologies. Antioxidants, 7(5), 62.

Gornall, A., G., Bardawill, C. J., \& David, M. M. (1949). Determination of serum proteins by means of the biuret reaction. Journal of biological chemistry, 177(2), 751-766.

Jana, K., Samanta, P. K, \& De, D. K. (2010). Nicotine diminishes testicular gametogenesis, steroidogenesis, and steroidogenic acute regulatory protein expression in adult albino rats: possible influence on pituitary gonadotropins and alteration of testicular antioxidant status. Toxicological Sciences, 116(2), 647-659.

Misra, H. P., \& Fridovich, I. (1972). The role of superoxide anion in the autoxidation of epinephrine and a simple assay for superoxide dismutase. Journal of Biological Chemistry, 247(10), 3170-3175.

Nagasawa, H. T. (2015). Inventor; Max International, Llc, assignee. Method to enhance delivery of glutathione and atp levels in cells. United States patent application US 14/838,274; p. 27.

National Research Council (2010). Guide for the Care and Use of Laboratory Animals: Eight Edition. Washington, DC: The National Academies Press.

Oyeyipo, I. P., Raji, Y., Emikpe, B. O., \& Bolarinwa, A. F. (2010). Effects of oral administration of nicotine on organ weight, serum testosterone level and testicular histology in adult male rats. Niger J Physiol Sci., 25(1), 81-86.

Patil, S., Patil, S., Bhaktaraj, B., Patil. S.B (1999). Effect of graded doses of nicotine on ovarian and uterine activities in albino rats. Indian J Exp Biol. 37(2):184-186.

Rajpurkar, A., Dhabuwala, C. B., Jiang, Y., \& Li, H. (2000). Chronic cigarette smoking induces an oxidantant imbalance in the testis. Journal of environmental pathology, toxicology and oncology: official organ of the International Society for Environmental Toxicology and Cancer, 19(4), 369-373.

Rotruck, J. T., Pope, A. L., Ganther, H. E., Swanson, A. B., Hafeman, D. G., \& Hoekstra, W. G. (1973). Selenium: Biochemical role as a component of glatathione peroxidase. Science, 179(4073), 588-590.
Saalu, L. C., Oluyemi, K. A., \& Omotuyi, I. O. (2007). ß-Tocopherol (vitamin E) attenuates the testicular toxicity associated with experimental cryptorchidism in rats. African Journal of Biotechnology, 6(12).

Sobhani, B., Roomiani, S., Ahmadi, Z., \& Ashrafizadeh, M. (2019). Histopathological analysis of testis: effects of astaxanthin treatment against nicotine toxicity. Iranian Journal of Toxicology, 13(1), 41-44.

Ukwenya, V. O. (2019). Testosterone propionate ameliorates oxidative stress and inflammation in nicotine-induced testicular toxicity. Journal of Experimental and Clinical Anatomy, 18(1), 74.

Varshney, R., \& Kale, R. K. (1990). Effects of calmodulin antagonists on radiationinduced lipid peroxidation in microsomes. International Journal of Radiation Biology, 58(5), 733-743. https://doi.org/10.1080/09553009014552121.

Yamamoto, Y., Isoyama, E., Sofikitis, N., \& Miyagawa, I. (1998). Effects of smoking on testicular function and fertilizing potential in rats. Urological Research, 26(1), 45-48.

Zakrzewska, H., Udala, J., \& Blaszczyk, B. (2002). In vitro influence of sodium fluoride on ram semen quality and enzyme activities. Fluoride, 35(3), 153-160.

\section{Publisher's Note}

Springer Nature remains neutral with regard to jurisdictional claims in published maps and institutional affiliations.

\section{Submit your manuscript to a SpringerOpen ${ }^{\circ}$ journal and benefit from:}

- Convenient online submission

- Rigorous peer review

- Open access: articles freely available online

High visibility within the field

- Retaining the copyright to your article

Submit your next manuscript at $\boldsymbol{\nabla}$ springeropen.com 